
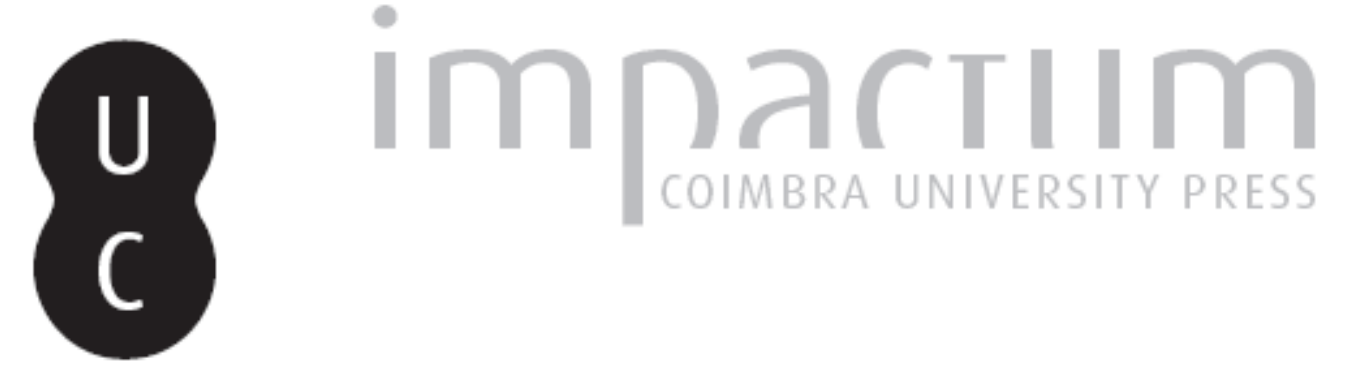

\title{
[Recensão a] Anne Zink, Clochers et Troupeaux. Les comunnautés rurales des Landes et du Sud-Ouest avant la Révolution
}

Autor(es): Neto, Margarida Sobral

Publicado por: Centro de História da Sociedade e da Cultura

URL persistente:

URI:http://hdl.handle.net/10316.2/39698

DOI:

DOI:http://dx.doi.org/10.14195/1645-2259_7_12

Accessed : $\quad$ 26-Apr-2023 13:39:03

A navegação consulta e descarregamento dos títulos inseridos nas Bibliotecas Digitais UC Digitalis, UC Pombalina e UC Impactum, pressupõem a aceitação plena e sem reservas dos Termos e Condições de Uso destas Bibliotecas Digitais, disponíveis em https://digitalis.uc.pt/pt-pt/termos.

Conforme exposto nos referidos Termos e Condições de Uso, o descarregamento de títulos de acesso restrito requer uma licença válida de autorização devendo o utilizador aceder ao(s) documento(s) a partir de um endereço de IP da instituição detentora da supramencionada licença.

Ao utilizador é apenas permitido o descarregamento para uso pessoal, pelo que o emprego do(s) título(s) descarregado(s) para outro fim, designadamente comercial, carece de autorização do respetivo autor ou editor da obra.

Na medida em que todas as obras da UC Digitalis se encontram protegidas pelo Código do Direito de Autor e Direitos Conexos e demais legislação aplicável, toda a cópia, parcial ou total, deste documento, nos casos em que é legalmente admitida, deverá conter ou fazer-se acompanhar por este aviso.

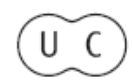




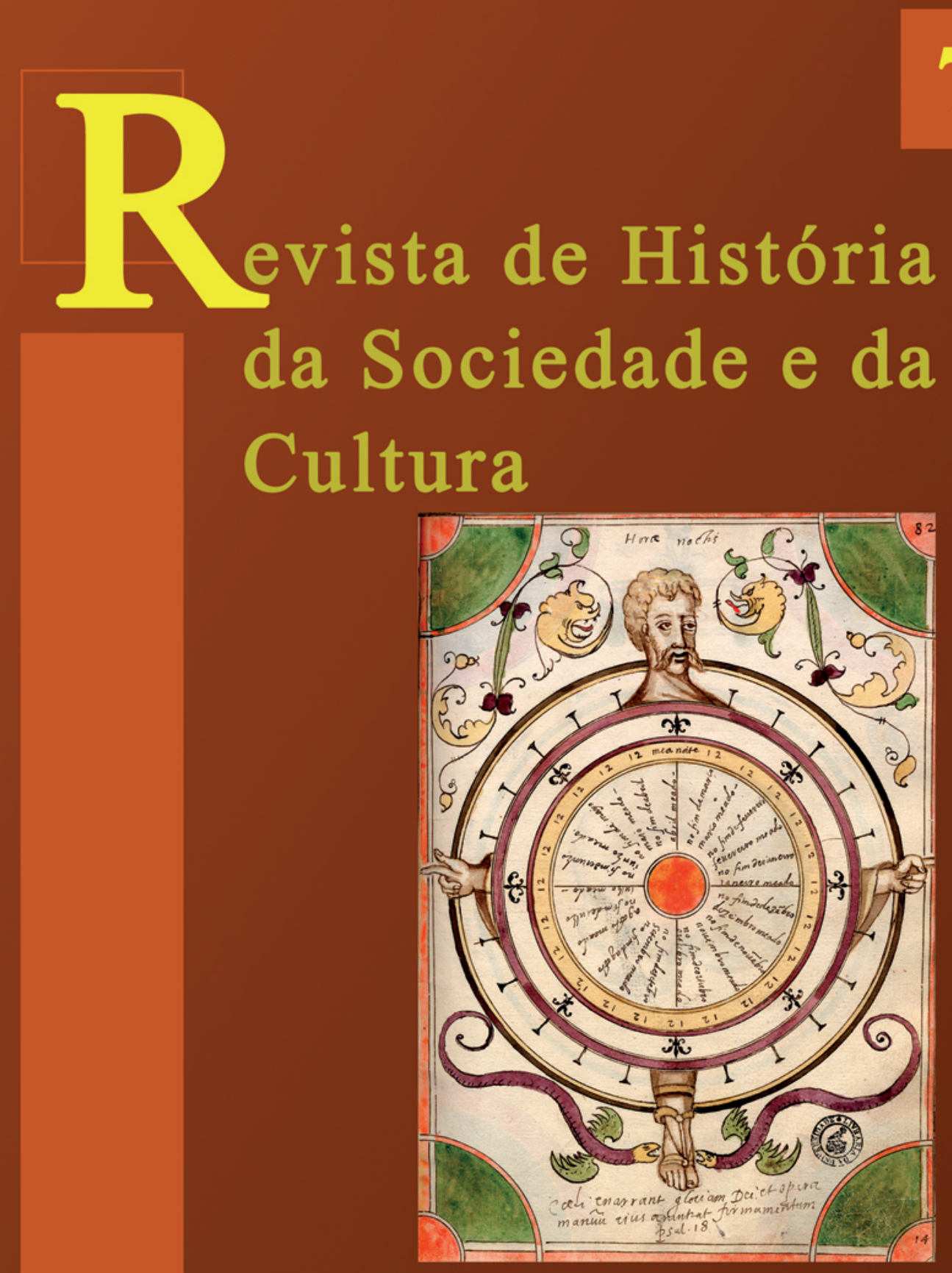

Centro de História da Sociedade e da Cultura Universidade de Coimbra

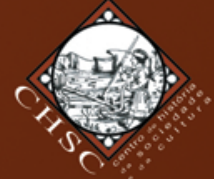


Anne Zink, Clochers et Troupeaux. Les comunnautés rurales des Landes et du Sud-Ouest avant la Révolution. Préface de Pierre Goubert. Bordeaux: Presses Universitaires de Bordeaux, 1997.

Clochers et troupeaux é uma obra que se integra numa linha de investigação, a monografia regional, iniciada em França, nos inícios do século XX, na área da geografia e depois na da história, tendo como cultores grandes historiadores franceses como Lucien Febvre ou Pierre Goubert. Com efeito, Anne Zink seleccionou como espaço de análise o actual departamento de Landes. O objectivo da autora não foi, entretanto, estudar a região globalmente considerada, mas as comunidades que a estruturam e the conferem identidade, as aldeias.

O livro divide-se em duas partes intituladas respectivamente: Funções e funcionamentos e Topografia e geografia. Na primeira parte, construída com base numa metodologia prosopográfica, apresentam-se os modelos de organização da vida colectiva das comunidades em articulação com as principais funções que lhe cumpre desempenhar. Um primeiro nível de organização da aldeia é enquanto comunidade constituída pelo conjunto de casas, famílias, que regulamentam a fruição dos bens e direitos comunitários; um segundo nível é o da paróquia, o quadro das actividades religiosas; o terceiro, é a célula fiscal, taillable, o grupo de famílias que recebe uma folha de impostos régios organizando-se no sentido do seu pagamento; o quarto nível é constituído pelo senhorio, o território de um senhor, espaço no qual detém a propriedade eminente das terras e direitos jurisdicionais, isto é o poder administrativo e judicial.

Numa análise muito detalhada, expressa numa narrativa onde se sentem palpitar as diversas expressões da vida do mundo rural, Anne Zink apresenta-nos as diversas possibilidades de organização das comunidades no sentido de cumprir as suas diversas funções, tanto as que emergem no seu seio como as que lhe são impostas por agentes externos (o rei, o bispo, o senhor).

O desempenho de cada uma das funções atrás referidas cabe, em cada uma das aldeias, a entidades distintas: o síndico (gestão dos comunais), o pároco (celebração dos ofícios religiosos), os jurados (encarregados da cobrança dos impostos) e os agentes senhoriais (cobrança de impostos e 
exercício da justiça), encontrando-se, no entanto, casos em que a mesma pessoa pode acumular o exercício de vários cargos.

Após ter examinado cada uma das comunidades a partir das diversas instituições que organizam o seu quotidiano, a autora apresenta, na segunda parte do livro, intitulada Topografia e Geografia, um estudo comparativo das comunidades da região de Landes bem como das situadas no sudoeste de França (Armagnac, Agen e Bordeaux, Bigorre e Béarn). Deste estudo comparativo ressaltam linhas de continuidade e contrastes. Entre as permanências destacam-se as decorrentes do facto das diversas instituições que organizam a vida das aldeias gerirem territórios cujos limites não eram coincidentes. Na procura das "coincidências e das distorsões", Anne Zink foi além do plano institucional. Com efeito, procurou a unidade e a diferença através da análise fina do ordenamento dos espaços e das construções urbanas bem como das paisagens rurais.

Neste livro, muito denso, (em parte por resultar de um texto mais longo referente a uma tese de doutoramento) perpassa toda a complexidade do mundo rural francês onde coexistem direito escrito e direito consuetudinário, normalização centralizadora e respeito dos privilégios. Originária do Norte, Anne Zink soube descobrir nos arquivos dos Pirenéus e do extremo sudoeste de França os traços identificadores de uma região, sendo um deles a força das comunidades face aos senhorios, e ao mesmo tempo, dar uma resposta ao problema que constituiu o fio condutor da sua investigação: a definição de um pays na França de Antigo Regime.

\section{Margarida Sobral Neto}

J. López, Roberto; González Lopo, Domingo (coord.), Balance de la Historiografia Modernista. 1973-2001. Actas del VI Coloquio de Metodología Histórica Aplicada. Santiago de Compostela: Xunta de Galicia, 2003.

Nos dias 25, 26 e 27 de Outubro de 2001 realizou-se, na Universidade de Santiago de Compostela, o VI Colóquio de Metodología Histórica Aplicada que teve como propósito celebrar a jubilação do professor António Eiras Roel. Este evento científico congregou muitos discípulos, amigos e 